\title{
Heuristic Potential of Postmodern Philosophy
}

\author{
Alexandr Mokshev - Dzhamilya N. Nurmanbetova
}

DOI: 10.18355/XL.2018.11.04.07

\begin{abstract}
Heuristic potential of postmodern philosophy is one of the most important issues in assessing this philosophical tradition. Postmodernists, who seek to discover and develop new problem areas, have developed their own issues with new terminology and methodology. In light of these moments, representatives of other philosophical schools have not found a sufficient methodological base to analyze the heuristic potential of philosophy. In this paper, we have made an attempt to overcome the methodological gap between the postmodern philosophy and dialectical materialism. In this case, we propose to use methodology and terminology of dialectical materialism and to analyze the heuristic potential of problem issues raised by postmodernists. We have made an attempt to use the category concept in analyzing the chosen issue, discovered by Michel Foucault - epistemes and their periodic changes. In the course of the research, we have found that methodology of dialectical materialism is able not only to disclose the object at the level of Foucault's methodology but also to determine and overcome some contradictions and to answer the questions that were undercharacterized due to certain drawbacks in the methodology used by a French thinker. In analyzing problem issues raised in postmodern philosophy, the methodology of dialectical materialism will reveal the heuristic potential issues of this philosophical tradition better. This will make a significant contribution to philosophical thought and philosophical education development.
\end{abstract}

Key words: postmodern philosophy, postmodernism, dialectical materialism, Michel Foucault, discourse concept, category «concept,» postmodern education

\section{Introduction}

The term "postmodern" is known to appear during the linguistic turn in 60-70s of the XX century (Rorty, 1992). It was described as a logical response to the crisis of modern ideas, the so-called "death" of the latter. In a culturological sense, it was considered as the end of Western rule in the fields of religion and culture (Cilliers, Spurrett, 1999).

In postmodern philosophy, the question "What is the postmodern philosophy?" is the most appropriate and worthy of considering, as the most philosophical issue of philosophy is the question "What is philosophy?". At the same time, "the end of philosophy" remains one of the most important issues in postmodern literature. Thus, if postmodern is considered as the end of modernity, then postmodern is nothing more than a great debate about what we have after the epistemological decline of the subject and of the objective world (Madison, 1988).

Postmodern is subject to constant debates as it is a transitional state (even a transitional epoch). It is also is subject to criticism in its important aspect - the philosophical one. It has destroyed many obsolete sides and elements of the previous era, taking its own place in the culture of the new century. However, the positive contribution of postmodern philosophy is still humble. Therefore, it is frequently analyzed and rethought by modern philosophers.

The phenomenon of postmodernism is very contradictory both in the cultural and philosophical aspects. On the one hand, this is a reality of modern culture and intellectual thought that could not be ignored. On the other hand, postmodern 
philosophy is often considered science and culture degradation due to a rejected object-oriented research paradigm. This fact leads to an extremely negative attitude on the part of the intellectual community (Davison, 2006). We can observe it in Western and post-Soviet comments on postmodern philosophy.

Western criticism comes with a post-positivistic approach to diverse ideas and problem issues. It is determined by certain indifference to postmodern philosophical works of representatives of other philosophical schools. Such philosophical pluralism makes the criticism of postmodernism focused on proving the inability of postmodernists to a clear and logical discourse, in particular - by highlighting the conscious overload of text with terms and categories of other sciences (Box, 2005).

However, there is a post-positivistic understanding of science methodology. Epistemological anarchism (Kulka, 1977) and the theory and methodology of the research programs of Imre Lakatos (1995) give the right to exist for a wide range of themes and research methods.

The West considers and criticizes postmodernists for the lack of clarity, complex thinking and amateurish use of terminology, but not for ideas. There is no claim to the condemnation of Lacanian psychoanalysis, Deleuze's philosophy or Latour's works in sociology. It is only about statements related to mathematical and physical sciences or about common issues in philosophy of science (Sokal, Bricmont, 1998).

This criticism of postmodernism is an illustration of a dispute between the natural scientific and humanitarian branches of knowledge. At the same time, it is criticizing methodology. Postmodernism is attributed to departure from the basic principles of science - rationality, logic, truth, and consistency, namely - it is a phenomenon that lacks these qualities. Thus, it cannot be a science.

Representatives of humanitarian disciplines form Post-Soviet methodological criticism using the epistemological foundations of dialectical materialism ( $\mathrm{Au}, 2007)$. They criticize not only the style but also the postmodern thought itself (Gobozov, 2011) as an irrational one without due account for traditional philosophical issues (Ilin, 1996). There are arguments that are similar to the West ones, namely confusing and ambiguous texts that cannot be understood in a rational way (Gubanov, 2007).

The post-Soviet philosophy of dialectical materialism is characterized by a general attitude toward postmodernism and by modern humanitarian studies, but not toward pointless discourses.

Hence, epistemological approach to postmodern philosophy has its similarities and differences in these two regions. The similarity lies in criticizing the "scientific quality" of postmodern works, in focusing on difficult understanding, the improper terminology of other fields of knowledge, illogical and inconsistent research. The difference lies in the fact that post-Soviet philosophy describes the philosophical tradition of postmodernism as nothing special, as a hollow one because it does not raise traditional philosophical issues considering self-contained quasi-philosophical discourses instead.

Thus, we conclude that an attempt to rethink and resolve the important philosophical issues with new approaches, as well as an attempt to discover new problem issues, is a background for the current heuristic potential of philosophy (Semenov, 2013).

Accordingly, we have made an attempt to overcome the methodological gap between the postmodern philosophy and dialectical materialism. In this case, we propose to use methodology and terminology of dialectical materialism and to analyze the heuristic potential of problem issues raised by postmodernists. This method will make a significant contribution to philosophical thought development and will increase its influence on science education. 


\section{Materials and Methods}

We have used the achievements of philosophical knowledge as a base for our philosophical research. Hypotheses are tested with formal logic and specific scientific information.

\section{Postmodern philosophy}

In considering postmodern philosophy, we suggest clarifying the philosophical position in the context of which it is considered. It is a belief in the philosophy of science, consideration of its history as a process of resolving issues to achieve the goal of philosophy - the realization of what is the truth. On the one hand, the truth of philosophical knowledge is determined by its logic and consistency, and on the other - by the corresponding reality. In this case, dialectical materialism is the most complete and logical direction in philosophy (Rodrigues, Camillo, Mattos, 2014).

Postmodernism is focused on analyzing and interpreting the phenomena of objective reality. In other words, the research subject is not disclosed at the proper conceptual level in comparison with previous philosophical studies. Hence, the postmodern problem field has to be related to disciplines that are less abstract than philosophy. Thus, postmodernists are trying to create and develop a philosophical concept by analyzing data from specific sciences.

As a result, this research method has an apparent disadvantage postmodernists develop a philosophical concept with its own unique terminology instead of checking the results of philosophical activity within these sciences. Herein, the second option gives an opportunity for further philosophical research.

We agree that postmodernism is inconceivable beyond the philosophical heritage and partly without common philosophical terminology. However, it is not prone to use "old" methodology and terminology. It is clear that new terms and methods are partially determined by an attempt to penetrate new problem issues. In this case, the use of previous terms seems to be an insufficient practice. This is a controversial research position, which undoubted disadvantage involves complex text comprehension (the reader has to get used to author's terminology).

Such an approach is counterproductive since it tends to reduce the direct philosophical activity of a philosopher. Thus, it turns into interdisciplinary intellectual activity, mediated by science achievements and trends. Nevertheless, achievements of postmodern philosophy cannot be considered as false or not valuable for philosophical knowledge despite the inefficient research methodology.

In this respect, "code transformation" is the most important prerequisite in unlocking research potential of postmodern philosophical heritage. It involves the exclusion of author's terms wherever possible. This will overcome the gap between the postmodern philosophy and other philosophical schools, and well add its achievements to the system of philosophical knowledge.

Let us provide a use example of the category "concept" in analyzing the Michel Foucault's postmodern work "The Archaeology of Knowledge and Discourse on Language" as an argument (Foucault, 1972). This work continues and explains, in theory, the book "Order of Things: An Archeology of the Human" Sciences» (Foucault, 1971).

Word and concept are interrelated, but not identical since the first one is ideal in a material way and the second - in immaterial. However, both are a subjective image of the objective world. Accordingly, we cannot say that a word is an image of the world since only the concept reflects a matter of something. It is also wrong to say that the concept means something since this feature is inherent only in the word (Semenov, 2013). 
The world exists in concepts reflecting objective reality to the extent this phenomenon is related to our performance. We (subjects) are reflecting its features to the extent this phenomenon is included in our activity.

For example, the concept of the word "sun" will be different for a child, an adult, and a professional astronomer. The subject knows the phenomenon in a way that necessary for his or her activity. Conversely, the subject has to expand the concept reflecting the required features or qualities of a phenomenon in order to increase its contribution to activity.

The choice of the category "concept" is determined by the previously mentioned linguistic turn since the linguistic project can be observed in the diverse philosophical works of the 20th century in one form or another only after it.

Since we are talking about postmodernists, it should be noted that their language problems lie in the context of social practices. Postmodernists try to show the essence of social practice and to reflect changes by showing their reflection in the language reality. However, an attempt to look at the social world as a web of world practices is the most interesting one.

\section{«The Archaeology of Knowledge \& the Discourse on Language»}

Foucault tries to create a new scientific discipline in his work - the archeology of knowledge, which subject covers the rules of expression and discourse.

He divides three aspects of these rules: linguistic, logical and homogeneous. Therefore, the only homogeneities the archeology is related with are a linguistic analogy (translativity), logical identity (equivalence) and common numbering (Foucault, 1972).

Foucault does not consider linguistic and logical rules of learning, described in linguistics and formal logic, but makes an attempt to determine the nature of homogeneity rules. In his opinion, they determine the differences between different periods of knowledge formalization. His desire to present statements, epistemes, and discourse as independent phenomena is an important approach to the archeology of knowledge, expressed in the form of practice. Ironically, discursive formations do not have the same historical model as the stream of consciousness or linearity of language do. According to archeology, discourse is at the level of its positivity: consciousness does not embody its project in the external form of language (langue); it is not a language (langue) or subject. Thus, we are not able to speak on it. It is a practice that has its own forms for inveigling and continuity (Foucault, 1972).

According to Foucault, these discursive practices completely mediate personal activities. For example, if in clinical discourse, the doctor is a sovereign, the direct questioner is an observing eye, touching a finger, the organ that deciphers signs, the point at which previously formulated descriptions are integrated, the laboratory technician. It is because there is the whole group of relations involved. Relations between the hospital space as a place of assistance, systematic observation and of partially proved, partially experimental therapeutics, and the group that determines codes of the human body are defined by morbid anatomy. Relations between the field of immediate observations and domain of acquired information; relations between doctor's therapeutic role, his or her pedagogic role, his or her role as an intermediary in medical knowledge diffusion, and his or her role as a responsible representative of public health in social space (Foucault, 1972).

According to Foucault, discursive education is the absolute prerequisite for subjective activity, an environment for thought development, which controls the subject completely. Moreover, the subject itself can be considered only in the context of practice. 
However, Foucault considers not the control over the subject as a reason for discursive education, but an ontological necessity to create opportunities for discourse and specific forms of knowledge. This episteme may be considered as a world-view, a slice of history common to all branches of knowledge, which imposes on the same norms and postulates, as a general stage of reason, a certain structure of thought that cannot be ignored in a particular period - a great body of legislation written once and for all by some anonymous hand. As a total set of relations that unite the discursive practices (Foucault, 1972).

He analyzes in detail three epistemes: the Renaissance (XVI century), classical (XVII - XVIII centuries.) and the modern (from the turn of the XVIII - XIX centuries to the present). Each of them differs depending on the principles of knowledge formalization.

In the Renaissance episteme, knowledge is being developed in the context of the following categories - similarity and imitation. A thing is defined in the context of modeling its similarity and imitation of another thing (coincidence, rivalry, analogy, sympathy, antipathy). Coincidence means spatial proximity that determines the similarity. Rivalry determines the similarity of things at a great distance without their coupling. Analogy puts a person in the center of world relations; sympathy is a principle of spatial movement and qualitative changes.

In the classical episteme, knowledge is being developed in the context of analyzing an order based on categories of identity and difference. In this case, development occurs in determining general properties and relationships, as well as the strong identity of attributes if there are no things defined as different.

In the modern episteme, representation "dies" giving way to interpretation and formalization. The essence of things is learned by appealing to formal systems of things and by interpretations through them. This approach leads to epistemological field fragmentation.

Despite the Foucault's negative attitude, we assume there is a possibility of creating a new history of science. Foucault explains, that nothing would be more false than to see in the analysis of discursive formations an attempt at totalitarian periodization, whereby from a certain moment and for a certain time, everyone would think in the same way, in spite of surface differences, say the same thing, through a polymorphous vocabulary and produce a sort of great discourse that could travel in any direction. On the contrary, archaeology describes a level of enunciative homogeneity that has its own temporal articulations, and which does not carry with it all the other forms of identity and difference that are found in language. At this level, it establishes an order, hierarchies, a whole burgeoning that excludes massive, amorphous synchrony given totally once and for all. In those confused unities that calls 'periods,' it reveals, with all their specificity 'enunciative periods' that are articulated, but without being confused with them, upon the time of concepts, on theoretical phases and on stages of formalization and of linguistic development (Foucault, 1972).

In his suggestions, Foucault bypasses the important and unwanted question the mechanism of discourse changing that leads to certain changes in the episteme. He writes a lot about the nature of statements, discourse, epistemes, and archives, but does not give clear information about their development. He dwells exclusively on the conclusions after skating several times over the statement development. For example, the affirmation that the Earth is round or that species evolve does not constitute the same statement before and after Copernicus, before and after Darwin. It is not, for such simple formulations, that the meaning of the words has changed; what changed was the relations of these affirmations to other propositions, their conditions of use and reinvestment, the field of experience, of possible verifications, of problems to be solved, to which they can be referred. The sentence 'dreams fulfill desires' may have 
been repeated through the centuries; it is not the same statement in Plato and in Freud (Foucault, 1972).

Perhaps, Foucault does not deal with discourse development because it will entail the use of experience in analyzing discourses held by a subject. In turn, the increasing role of a subject will cause a rethinking of the nature of discursive formations depriving them of ontological independence. Therefore, he has created a structure without getting into the issues of discourse development and change.

Moreover, the introduction of a subject and his or her experience into discourse development is not enough to disclose its nature, since the relationship between the vast unstructured field of subjective experience and the stages of discourse development is unknown. We also understand that Foucault has drawn a wrong thesis about the self-sufficiency of discourse in his attempt to analyze the discursive practices in theory. This thesis has substantiated all of the above statements and shortcomings of the French thinker's concept.

Thus, we conclude that the category "concept" is much more rational to use in analyzing empirical data provided in "Words and Things" instead of the category "discourse." This fact does not detract from Foucault's scientific discovery identification of qualitative changes in the concept structure, described as a stage of discourse development in the system of epistemes.

We also assume that qualitative changes in the concept structure are determined by production processes development. This entails the appearance of new attribute characteristics inherent in modern production processes. Changes occur under the pressure of competing for production processes that require the most complete and objective reflection of things in order to determine the most effective way to use their features.

Thus, Foucault's empirical material - formalization of discursive practices shows the qualitative development of concepts and the complex structure of their interaction.

\section{Findings}

Research findings confirm the possibility of using methodology and terminology of dialectical materialism to overcome the methodological gap between the latter and the postmodern philosophy. The attempt to apply the category of a "concept" in analyzing the studied field of issues, discovered by M. Foucault epistemes and their change - has showed that methodology of dialectical materialism is able not only to disclose the object at the level of Foucault's methodology but also to determine and overcome some contradictions and to answer the questions that were undercharacterized due to certain drawbacks in methodology used by a French thinker.

Accordingly, we have determined certain advantages of using the methodology of dialectical materialism in analyzing problem issues raised by postmodern philosophy - it will reveal the heuristic potential issues of this philosophical tradition better, making a significant contribution to philosophical thought development.

We conclude that ideas and issues of postmodern philosophy are heuristics in nature, but terminology and approaches of dialectical materialism are much more effective in studying and developing them.

\section{Conclusions}

XLinguae, Volume 11 Issue 4, October 2018, ISSN 1337-8384, eISSN 2453-711X 
The works of not only Foucault but also of other postmodernists can be used as an example of postmodern research methodology. Their language problem can be revised with the term "category." Examples include the following: simulacrum, hyperreality, and symbolism (Fuchs, 2010; Zompetti, Moffitt, 2009).

Introduction of language and thinking into the social sphere, as well as the emphasis on the developing nature of the social sphere, which postmodernists do not seek to define, are common features for all these works.

Postmodernists have managed to move from thinking to language, from language systematization to describing culture manifestations by means of various practices. Their descriptive style is a certain defect from a purely philosophical point of view, but this style has revealed the dynamics and changes in social structure that they expressed through the category of practices.

Thus, they have proven that this concept cannot be considered only as a category of thought - it should be applied in analyzing all human activities since the content of this concept is most fully manifested in human activity.

How effective is the postmodern philosophy from the scientific point of view? In answering this question, two aspects are necessary to divide: how relevant and the heuristic is the perspective of postmodern philosophy; how can we use its terminology and methodology successfully in philosophical studies.

We believe that the issues raised in postmodern philosophy have a certain heuristic potential. Thus, works of postmodernists can serve as a good basis in setting research objectives and in developing philosophical issues. For the record, this is about only their purely philosophical aspect. For example, Foucault has left his mark in many fields of humanities, but this direction is of particular interest only in works devoted to philosophy.

The desire of postmodernists to find the source of their theories in specific sciences provides their work with a certain style. The authors try to express the spirit of their time. However, this makes their terminology and methodology difficult to understand and ineffective in studying philosophy.

\section{Bibliographic references}

AU, W. 2007. Epistemology of the oppressed: The dialectics of Paulo Freire's theory of knowledge. Journal for Critical Education Policy Studies, vol. 5, n. 2, pp. 1-18.

BOX, R.C. 2005. Critical Imagination in a Postmodern Environment, International Journal of Public Administration, vol. 28, pp. 11-12, 909-928

CILLIERS, P. - SPURRETT, D. 1999. Complexity and post-modernism: Understanding complex systems. South African Journal of Philosophy, vol. 18, n. 2, pp. 258-274.

DAVISON, K.G. 2006. Dialectical imagery and postmodern research, International Journal of Qualitative Studies in Education, vol. 19, n. 2, pp. 133-146

FOUCAULT, M. 1971. Order of Things: Archeology of Human Sciences. New York, NY; Pantheon books.

FOUCAULT, M. 1972. Archaeology of Knowledge \& the discourse on language. New York, NY; Pantheon books.

FUCHS, M. 2010. A Horrific Welcome to the Desert of the Real: Simulacra, Simulations, and Postmodern Horror. Landscapes of Postmodernity: Concepts and Paradigms of Critical Theory. Vienna: LIT, pp. 71-90.

GOBOZOV, I.A. 2011. Who needs such a philosophy? From the search for truth to postmodernism. Moscow, M; Book house "Librocom";

GUBANOV, N.I. 2007. Poverty of the philosophy of postmodernism. Russian journal "Philosophy and Society", Uchitel Publishing House, vol. 1, n. 45, pp. 54-68

ILIN, I.P. 1996. Post-structuralism. Deconstructivism. Postmodernism. Moscow: Publishing house "Intrada", vol. 251, pp. 2. 
KULKA, T. 1977. II How Far Does Anything Go? Comments on Feyerabend's Epistemological Anarchism. Philosophy of the social sciences, vol. 7, n. 3, pp. 277287.

LAKATOS, I. 1995. Methodology of Scientific-Research Programs. Voprosy Filosofii, n. 4, pp. 135-154.

MADISON, G.B. 1988. Postmodern philosophy? Critical Review: A Journal of Politics and Society, vol. 2, n. 2-3, pp. 166-182

RODRIGUES, A. - CAMILlO, J. - MATTOS, C. 2014. Quasi-appropriation of dialectical materialism: a critical reading of Marxism in Vygotskian approaches to cultural studies in science education. Cultural Studies of Science Education, vol. 9, n. 3, pp. 583-589.

RORTY, R. 1992. The linguistic turn: Essays in philosophical method. University of Chicago Press.

SEMENOV, Y.I. 2013. Introduction to Philosophy. Book 1. The subject of Philosophy, its basic concepts and role in the system of human knowledge. Translation by Mokshev A.Y., Moscow: URSS Publisher. Publishing house "Librocom".

SOKAL, A. - BRICMONT, J. 1998. «Fashionable nonsence: postmoderm intelectuals' abuse of science». New York, NY; Pickador.

ZOMPETTI, J. P. - MOFFITT, M. A. 2009. Revisiting concepts of public relations audience through postmodern concepts of metanarrative, decentered subject, and reality/hyperreality. Journal of Promotion Management, vol. 14, n. 3, pp. 275-291.

Words: 3993

Characters: 26925 (14,96 standard pages)

Alexandr Mokshev

Department of Philosophy L.N.Gumilyov Eurasian National University

Satpayev str. 2, Astana

Kazakhstan

mokshev.alex@gmail.com

prof. Dzhamilya N. Nurmanbetova

Department of philosophy L.N.Gumilyov Eurasian National University

Satpayev str. 2, Astana

Kazakhstan

nurman.dzham@gmail.com 